\title{
PESQUISAS SOBRE O MELHORAMENTO DO CAFE
}

\section{A. Carvalho*}

Em meio à crise econômica, que em 1933 afetava pro fundamente a indústria cafeeira do país, a Seção de Genē tica do Instituto Agronómico de Campinas dava início à um amplo programa de estudos, tendo por objetivo conhecer o cafeeiro do ponto de vista biológico e obter linha gens rústicas, de elevada produção, adaptadas às nossas condições de cultivo e com bebida de boa qualidade. Nes sa época, em que se queimavam toneladas de café excedente, a idéia de dar início a essas pesquisas não parecia razoável. Todavia, os organizadores desse projeto, que por certo seria de longa duração, tiveram em vista a futura necessidade de formação de novos cafezais, dado o abandono e a destruição, nessa época, de numerosas plantações, por razões económicas. Ao formarem os novos cafezais, para atender a demanda de café, os lavradores de veriam contar com material altamente produtivo e com tec nicas esmeradas de plantio, para fazer face à concordância no mercado internacional de café (21).

* Seção de Genética do Instituto Agronômico de Campinas. 


\section{BANCO DE GERMOPLASMA}

Uma das primeiras providências tomadas constituiu na coleta e reunião, em coleção viva, de todas as variedades e variações de $C$. arabica encontradas nas propriedades cafeeiras, bem como outras espécies de coffea já anteriormente introduzidas no país, a fim de melhor conhecê-la e avaliar a sua potencialidade (21).

Com o decorrer dos anos, esse banco de germoplasma foi sendo periodicamente enriquecido com outras variedades e espécies de café,tornando-se extremamente útil para realizações de investigações sistemátiças, de morfolo gia, biologia da reproduçăo, anālises genéticas e citolō gicas, de fisiologia, evolução e para seu aproveitamento para fins de melhoramento.

OBSERVAÇÕES SOBRE A BIOLOGIA DA REPRODUÇÃO

Estudos detalhados foram realizados sobre a estrutura e desenvolvimento das inflorescências, épocas de florescimento, antese, agentes da polinização, fecundação das flores e taxa de fecundação cruzada natural (20).

Determinou-se, ao contrārio do que se julgava na época, que $C$. arabica era uma espécie autocompatível e praticamente autógama, enquanto que, a segunda espécie de café em importância econômica, $C$. canephora era autoincompatível e alógama e que o vento, os insetos e, em menor proporção, a própria gravidade, eram os principais agentes de fecundação cruzada natural.

Dos marcadores genéticos utilizados na determinação da taxa de fecundação cruzada, o fator recessivo ce
(cera) revelou-se o mais adequado por afetar a cor do endosperma (8). 
Determinou-se, por intermédio desse marcador, que a taxa de fecundação cruzada atingia valores médios de dez por cento e que em uma cova de café com quatro plantas, a taxa diminuia à medida que se acrescentavam plantas com sementes de cor cera, em relação às de sementes verdes normais. Outros marcadores genéticos recessivos $(\mathrm{pr})$, angustifolia (ag) e xanthocarpa (xc) deram resulta dos semelhantes (11).

Verificou-se que outras espécies diplóides como $C$. congensis, $C$. dewevrei, $C$. liberica, $C$. eugenioides, $C$. kapakata, C. racemosa, C. salvatrix, são autoincompatíveis e se multiplicam na natureza exclusivamente por fecundação cruzada. As espëcies $C$. bengalensis, $C$. travan corensis e provavelmente $C$. brevipes e $C$. mauritiana, em bora diplóides, parecem ser autógamas. Deve-se salientar que $C$. bengalensis e $C$. travancorensis vêm, atualmen te, sendo consideradas, por alguns autores, como pertencentes ao gênero Paracoffea (28).

\section{ASPECTOS CITOLÓGICOS}

0 número de cromossomos foi determinado para numerosas espécies e cultivares, notando-se ser de onze o nú mero básico para o gênero Coffea (21).

C. arabica revelou-se a única espécie tetraplóide, enquanto as demais eram diplóides. Em $C$. arabica encontram-se as formas dihaplóides, com 22 cromossomos somáti cos, hexaplóides e octoplóides, com 66 e 88 cromossomos, além de formas com 33 e 55, obtidas através de hibridações artificiais. Uma série de aneuplóides foi constata da com 43 e 45 cromossomos, sendo mais rara a forma com 42. As características dos poliplóides e aneuplóides fo ram estudadas $(24,30)$.

Do ponto de vista da morfologia, analisaram-se os 
cromossomos somáticos de $C$ dewevrei (30) e, mais recentemente, a morfologia dos cromossomos ligados ao nucléo10, em värias espécies de Coffea, procurando-se associar - número e a morfologia desses cromossomos das espécies diplöides com os de $C$. arabica, tetraplóide, e assim estabelecer as suas relaçōes filogenéticas (25). Pesquisas foram efetuadas sobre a microsporogênese e formação dos gametas, bem como a macrosporogênese, formação do sa co embrionário, sobre a dupla fertilizaçao e formação do endosperma em $C$. arabica e algumas espécies diplóides $(21,30)$. Em $C$. arabica indicou-se que, o óvulo apresen ta um único tegumento, sendo o nucelo muito reduzido $\bar{e}$ que, apōs a fertilização, o perisperma se desenvolve com rapidez à medida que cresce o ovário, enquanto o núcleo primário do endosperma inicia a sua divisão 20 a 25 dias após a antese. A primeira divisão do zigoto ocorre ainda mais tardiamente, 60 dias depois da antese (30). A meiose nas plantas haplóides de $C$. arabica revelou a ocorrência de 1 a 6 cromossomos bivalentes em $71 \%$ de células em metafase (I).

ANĀLISES GENETICAS

As anālises genéticas das principais características dos cultivares de $C$. arabica, embora demoradas, vêm sendo realizadas, levando-se em média, 16-20 anos para serem concluídas. Além disso, são dispendiosas e requerem identificação de todas as plantas em estudos (21). Tem-se verificado que a variabilidade morfológica em $C$. arabica não $\overline{\mathbf{e}}$ grande, possivelmente por tratar-se de espécie tetraplóide. Não se têm conseguido mutações novas através de tratamento de mutagênicos físicos e químicos, para acréscimo da variabilidade genética.

Tomando-se o cultivar Arabica como padrão, verificou-se que alguns dos 40 fatores já estudados são semido minantes, dominantes ou recessivos, em relação aos ale- 
los desse padrão. Afetam características do porte, rami ficação, internódios, folhas, flores, frutos e sementes e alguns fatores apresentam acentuado ef eito pleiotrópico $(5,23)$.

Os fatores que reduzem o comprimento do internodio, dando origem a plantas de porte menor e de aspecto mais compacto, revelaram-se extremamente interessantes do ponto de vista do melhoramento, pelo fato da colheita e os tratamentos fitossanitários nessas plantas serem mais fáceis. Dos fatores estudados, Caturra (Ct), São Bernardo (Sb), San Ramon (Sr) e Vila Lobos (V1), todos dominantes, o Caturra vem sendo analísado há mais tempo e transferido a outros cultivares de interesse económico, porém de porte maior $(9,28)$.

o fator Erecta (Er) reduz o ângulo que os ramos la terais fazem com a haste principal, dando à planta um as pecto erecto, embora esses ramos laterais continuem com as suas características de ramos plagiotrópicos. Plantas portadoras dos alelos Erecta e Caturra foram obtidas e poderão ser plantadas em maior densidade, favorecendo a produção por área.

o fator cera, recessivo, afeta a cor da semente, tornando-a amarela, ao invés de verde, normalmente verificada na semente do café Arabica. Plantas cera vèm sen do empregadas na análise da taxa de fecundação cruzada natural (5) e foram de grande utilidade para demonstrar, pela primeira vez, e por meios genéticos, que o café pos sui um endosperma verdadeiro (22). Como as sementes cera também possuem o mesmo teor de ácido clorogênico encontrado em sementes verdes comuns, serviram também para indicar que essa coloração verde não é devida ao teor desse componente da semente (3). Apresentando os mesmos pigmentos flavonóides e clorofila do que o verde, o cera serviu ainda para indicar que a cor verde da semente não deve estar relacionada com esses componentes do endosper ma (26). 
RELAÇõES FILOGENETICAS ENTRE ESPÉCIES DE COffea

Apesar da coleção de espécies de Coffea não ser completa, pesquisas com as espécies existentes vêm sendo realizadas a fim de estudar as relações entre as diplóides e entre elas e a espécie tetraplóide $C$. arabica. Os resultados das hibridações interespecíficas e o número de plantas obtidas, vêm indicando que $C$. eugenioides estaria relacionada com a origem de $C$. arabica, a outra es pécie podendo ser $C$. canephora ou $C$. congensis. Na lite ratura há informações sobre o possivel papel que as espể cies de Madagascar possam também ter desempenhado na or gem de $C$. arabica (12).

Várias outras informações foram obtidas sobre a re lação entre as espécies diplóides. Verificou-se ainda, que algumas se cruzam facilmente $\operatorname{com} C$. arabica, o que não ocorre com outras, dificultando a transferência de fatores genéticos favoráveis dessas espécies silvestres para $C$. arabica $(10,12,28)$.

Estudos de pigmentos flavonöides encontrados no exocarpo dos frutos e de värias enzimas verificadas nas folhas, foram realizados, a fim de verificar a relação filogenética entre as espécies, com base na variação des sas caracteristicas. Verificou-se que algumas dessas in formações assemelham-se às obtidas através de análisēs dos cruzamentos interespecíficos (24).

INFORMAÇõES RELACIONADAS COM O MELHORAMENTO

As informações básicas que foram acumulando, como resultados do desenvolvimento do plano geral de estudos do cafeeiro, vieram desempenhar um papel relevante no su cesso do melhoramento com a obtenção de novos cultivares 
e 1 inhagens de boas características e elevada produção.

A seleção de cafeeiros matrizes individuais e estu do de suas progênies, a introdução de material de outras regiões e a hibridação intra e interespecifica, vêm sendo utilizadas como métodos de melhoramento geral para C. arabica.

o cultivar Arabica ou Nacional, primeiramente cultivado no Brasil e em São Paulo, foi gradativamente subs tituído pelo Bourbon Vermelho e Sumatra e, em algumas re giões, pelo Maragogipe $\mathrm{AD}$. Por isso, as primeiras seleções estudadas foram desses cultivares.

Resultados auspiciosos foram conseguidos com o Bourbon Vermelho, enquanto as seleções de Maragogipe $A D$ e Sumatra não se revelaram valiosas, apesar do grande nú mero de cafeeiros estudados individualmente. Algumas progênies do Bourbon Vermelho chegaram a produzir $90 \%$ a mais do que o Arabica (15). Os estudos de progênies foram efetuados, simultaneamente, em três e posteriormente em cinco localidades, representativas das regiões cafeei ras de São Paulo, a fim de avaliar e escolher aquelas de melhor capacidade de adaptação. Nesses estudos verificou-se que, de modo geral, as melhores progênies em uma localidade davam também boas produções nas demais locali dades, indicando ampla capacidade de adaptação do material. Verificou-se, tambem, para o Bourbon Vermelho, que uma seleção precoce, baseada nos seis primeiro anos de colheitas é eficiente (4) e que a seleção de plantas matrizes no campo, deve ser feita em anos de elevada pro dução, em vista das melhores plantas serem aquelas que produzem mais nesses anos de el evada produção do cafezal (4) em nossas condições de cultivo.

A seleção em populações segregantes de hỉbridos na turais entre o Bourbon Vermelho e o Amarelo de Botucatu ou entre o Bourbon Vermelho e o Sumatra, mostrou-se extremamente eficiente. Na primeira população foi possĩvel selecionar linhagens de Bourbon Amarelo que, além de 
mais produtivas do que as do Bourbon Vermel ho mais), revelaram-se bem mais rústicas, fator de interesse para o tipo de cultivo do café em São Paulo. - Bourbon Amarelo alia ainda a capacidade de ser pouco mais precoce no amadurecimento dos frutos, o que é de in teresse em locais de maior altitude, onde o amadurecimen to no geral é mais demorado $(15,17)$.

Da hibridação natural entre o Bourbon Vermelho e o Sumatra, resultou o café Mundo Novo, que começou a ser selecionado na região de Jaú, de onde foi levado para a Araraquarense, principalmente no antigo municipio de Mun do Novo, hoje Urupês. Nessa localidade, as primeiras sé leções foram realizadas em 1943 em cafezais desunifor mes, porém de elevado vigor e produtividade. Observaçōes sobre as progênies iniciais revelaram que se tratava de material excelente e que a seleção foi bastante efetiva (16). Um dos defeitos encontrados nas populações originais, isto é, a alta incidência de frutos bem formados, porém desprovidos de uma ou de duas sementes, foi analisado e eliminado por seleção. Trata-se de fator ou fatores genéticos que inibem o desenvolvimento normal do endosperma, reduzindo-o a um pequeno disco (31). Plantas normais, sem o defeito, resultam em progê nies normais e, dessa forma, a seleção de plantas matrizes normais pode ser realizada no campo, antes de serem estudadas as suas progênies. Disso resultou um rápido acréscimo na produção, tornando o Mundo Novo, conhecido internacionalmente, como um dos cultivares de maior potencialidade produtiva de C. arabica (34). Avanços na seleção de Mundo Novo vêm sendo obtidos pela análise de populações $\mathrm{S}_{2}$ e $\mathrm{S}_{3}$, ainda com suficiente variabilidade genética (19), como também através de hibridações entre cafeeiros selecionados desse cultivar e análises de $\mathrm{F}_{2}$ e $F_{3}$. As seleções de Mundo Novo no geral apresentam semen tes pouco maiores do que as Bourbon Vermelho, caracterís tica provinda do café Sumatra. Algumas seleções, de boa produção, e com sementes ainda maiores, receberam denominaçáo de Acaiá - frutos de sementes grandes. Para alguns mercados que preferem cafés com essa característ ca, o Acaiá tem algumas vantagens. 
Hibridaçoes entre e dentro de cultivares, bem como entre $i$. rratir.l e outras espécies de Coffea, realizadas com frequência, vêm dando resultados animadores. Numero sas populações derivadas dessas hibridações são estudadas em experimentos.

Uma das combinações mais valiosas nesse plano de hibridaçōes artificiais, refere-se ao café Catuai, resul tado de hibridações de plantas selecionadas de Caturra Amarelo e de Mundo Novo, realizadas em 1949 (13). A finalidade em vista era transferéncia ao Mundo Novo, do fa tor Caturra, a fim de se obter o Mundo Novo de porte mais reduzido. As seleções de frutos vermelhos, Catuai Vermelho, e as de frutos amarelos, Catuai Amarelo, revelaram-se de bastante interesse econômico. Produtivos co mo Mundo Novo e também com sua rusticidade, esses cafés passaram a ser cultivados em escala comercial em todas as regiōes cafeeiras do Brasil. 0 seu porte menor facjlita a colheita, operação das mais dispendiosas e, também, os tratos fitosanitários, além de poderem ser plantados de modo mais derıso, melhorando a produção por ārea (13).

A introdução da ferrugem no Brasil, notada em 1970, veio modificar, em parte, o plano geral de melhoramento. Tornou-se prioritäria a incorporação de fatores genéticos que conferem resistência a Hemileia vastatrix aos cultivares existentes ou o desenvolvimento de outros cul tivares, principalmente através de hibridaçōes interespê cificas, particularmente com a espécie Coffea canephora. Sabe-se que algumas plantas dessa espécie apresentam cafeeiros resistentes a todas as raças fisiológicas conhecidas desse fungo $(1,6)$. Hibridações foram feitas para associar os fatores de resistência vertical ou específica, $\mathrm{SH}_{1}, \mathrm{SH}_{2}, \mathrm{SH}_{3}$ e $\mathrm{SH}_{4}$, encontrados em plantas selecionadas isoladas. Também as hibridações tiveram em vista a transferência desses fatores às seleções de Mundo Novo e Catuai, que possuem apenas o fator $\mathrm{SH}_{5}$ de resistência (7). Raças de $H$. vastatrix com combinações de fatores de virulência, foram se formando entre nōs, de modo a neutralizar esses fatores de resistência. Como a resis- 
tência conferida pelo fator $\mathrm{SH}_{3}$ ainda não foi anulada pe la raça com o fato de viruléncia $v_{3}$, os hïbridos portadores desse fator, vêm ainda sendo objeto de estudos nas combinações com Catuai e Mundo Novo. Esses numerosos hî bridos com material inicialmente resistente ao agente da ferrugem, embora já não mais sejamresistentes, apresentam outros fatores que ampliaram a variabilidade genética do nosso material, permitindo seleções de novas combi nações com produções mais elevadas.

o café Icatu constitui uma das combinações mais promissoras nesse programa de seleção, tendo a resistência ao agente da ferrugem derivada da espécie $C$. canepho ra (33). Essa resistência deve-se, possivelmente, a um maior número de fatores genéticos e é tida como não espe cifica, horizontal ou duradoura. As hibridações iniciais foram realizadas há 35 anos entre $C$. arabica e $C$. canephora, com número duplicado de cromossomos. 0 hïbri do, de grande vigor vegetativo, boa produtividade e resistente, foi retrocruzado preferencialmente com plantas selecionadas de Mundo Novo. As gerações $\mathrm{S}_{2}$ e $\mathrm{S}_{3}$ do segundo, terceiro e quarto retrocruzamentos para esse cultivar e alguns com o Bourbon Amarelo, estão em estudos e genericamente receberam a denominação de Icatu. Tratando-se de hibridação interespecífica, um dos obstāculos a vencer $\bar{e}$ o de uniformizaçãodas progênies. Para isso há necessidade de selecionar aquelas que dão número reduzido de plantas anormais, possivelmente aneuplóides, e pequena quantidade de sementes do tipo moca, isto $\vec{e}$, resul tantes do desenvolvimento de uma única semente por fruto. A quantidade elevada de sementes moca, além de depreciar o produto, reduz também a produção do cafeeiro, por piorar o rendimento - relação entre o peso de frutos e o de café beneficiado.

Tem se verificado que a seleção visando resisténcia ou tolerāncia aos nematóides que atacam o sistema ra dicular, principalmente Meloidogyne incognita, $M$. exigua e $M$. coffeicola é de fundamental importância para a cafeicultura nas regiões de solos mais arenosos de São Pau 1o. Um intenso trabalho acha-se em execução, tendo por 
objetivo detectar fontes de resistência e transferî-1as para os cultivares conhecidos. Verificou-se que algumas linhagens de Coffea canephora, de Icatu e também de Cati mor, apresentam-se com resisténcia a $M$. incognita, especie que mais causa danos. As observações de resistência têm sido efetuadas em várias localidades para detectar a possível ocorrência de raças desses patógenos. As linha gens resistentes de $C$. canephora vêm sendo utilizadas cô mo porta-enxerto para as de Mundo Novo e Catuai, enquanto as linhagens resistentes ou tolerantes de Icatu vêm sendo multiplicadas para produção de sementes aos lavradores (18). Tem-se verificado que o Icatu constitui, também, fonte de resistência à moléstia conhecida como CBD, causada pelo Colzetotrichum coffeanum (14). Algumas 1 inhagens de Icatu Vermelho, como LCH 4782-7-585, LCH 4782-7-788, MCH 4782-10-108, MSSCH4782-16-82-1, C 2905, C 2945, C 2926 e C 2941 e de Icatu Amarelo, como C 2944, C 2907 , C 3282 e C 2934 , vêm se revelando muito promisso ras e, assim, já se acha, em Campos de observaçoes para fins de seleção e produção de sementes aos lavradores.

G café Catimor foi sintetizado pela hibridação do Caturra Vermelho com o Hïbrido do Timor (1), que resultou de cruzamento natural entre $C$. arabica e $C$. canephora. Numerosas 1 inhagens de Catimor foram analisadas, ve rificando que, embora com resistência não específica ao agente da ferrugem, as melhores progênies quanto à produ ção não são rūsticas, o que constitui uma grande desvantagem e limita o seu plantio entre nós (2).

Observações sobre a produção de calos a partir de perisperma, tecidos de folhas e de anteras de café foram iniciadas na Seção de Genética hā, aproximadamente, 12 anos. A finalidade em vista era a de obter a regeneração completa de plantas a partir de tecidos de perisperma e de folha e, assim, propagar vegetativamente e em larga escala, determinados cafeeiros selecionados, além das informações sobre a morfogênese e a embriogênese somática no cafeeiro. Para os tecidos de antera, a finali dade era a de se conseguir plantas haplóides a partir de espécies diplóides. A regeneração de plantas de café a 
partir de tecidos do calo. de folha foi conseguida há alguns anos (35) e, atualmente, vem sendo prosseguida, ten do em vista o estudo da variabilidade somacional. Se vă riações forem assim conseguidas, serão de bastante interesse em vista da dificuldade de se conseguirem novos mu tantes em $C$. arabica, diferentes daqueles já conhecidos e de interesse para o plano geral de melhoramento.

Tem-se verificado que algumas espécies, como $C$. stenophyzza, C. racemosa e $C$. dewevrei, são resistentes ou tolerantes ao bicho mineiro (Perileucoptera coffeelZa), enquanto todas as linhagens de $C$. arabica são susce tiveis. A transferência de fatores de resistência de $C$. stenophylta para $C$. arabica vem sendo tentada, porém sem sucesso, pela dificuldade de se obterem hỉbridos entre elas. Ao contrārio, a hibridação de $C$. arabicuc com ". racemosa é viāvel, tendo-se jā conseguido hỉbridos $F_{1} e$ retrocruzamentos com $C$. arabica. Värias dessas populações são estudadas, tendo em vista a obtenção de linhagens com boas características agronomicas e resistentes ao bicho mineiro (27).

\section{CONS IDERAÇÕES GERAIS}

o plano geral de melhoramento, embora disfendioso, vem dando resultados altamente auspiciosos. Isso se deve não somente ao apoio governamental que teve desde o início de sua execução como também, pela continuidade dos trabalhos nestesūitimos 50 anos. Para uma planta pe rene, que requer três a quatro anos para florescer é mais seis ou oito anos de seguidas colheitas individuais, para se poder selecionar as progênies mais promissoras, a continuidade das observaçôes torna-se um fator ponderā vel para o sucesso do melhoramento. Também foi possíve $\overline{1}$ contar com a colaboração de técnicos de outras instituições, em algumas das fases de melhoramento, e principalmente com a colaboração de lavradores para a avaliação 
das progênies e sua multiplicação para a produção de sementes.

Os resultados colhidos com relação à biologia da reprodução, das análises citológicas e genéticas e obser vações sobre a evolução e aplicação da técnica experimeñ tal, além de contribuírem para melhor conhecimento do ca্ feeiro do ponto de vista biológico, revelaram-se extremamente valiosos para abreviar o tempo gasto nas seleçōés e avaliação das progênies.

Também as observações sobre as espécies silvestres do banco de germoplasma mostraram-se úteis, principalmen te quanto a sua reação a moléstias e pragas, permitindo a transferência dos fatores genéticos de resistência, de que são portadoras, para os cultivares de $C$. arabica. Além da ampla variabilidade genética que se encontra nas populações derivadas dessas hibridaçôes, foi possivel de senvolver alguns cultivares novos, como o Icatu, de significativo interesse para a economia do país.

\section{REFERENCIAS}

1. BETTENCOURT, A.J. Consideraçöes gerais sobre o Híbrido do Timor. Circ. no 23, Instituto Agronomica Campinas, 20 pp., 1973.

2. BETTENCOURT, A.J. \& LOPES, J. Transferência de fato res de resistência a $H$. vastatrix do Hibrido do Timor para o cultivar Caturra Vermelho de Coffea arabica. Congresso Brasileiro de Pesquisas, Cafe eiras, Caxambu, MG, 4: 287-291. 1976.

3. CARELLI, M.L.C., LOPES, C.R. \& MONACO, L.C. Chlorogenic acid content in species of Coffea and selections of $C$. arabica. Turrialba 24(4): 398401,1974 . 
4. CARVALHO, A. Melhoramento do Cafeeiro VI: Estudo e interpretação para fins de seleção de produções individuais na variedade Bourbon. Bragantia 12: 179-200, 1952.

5. CARVALHO, A. Advances in coffee production technology. Recent advances in our knowledge of coffee trees. 2 - Genetics. Coffee \& Tea Industries 81: 30-36, 1958.

6. CARVALHO, A. Melhoramento do cafeeiro - Cruzamentos entre $C$. arabica e $C$. canephora. ASIC Coloquim, Salvador, Bahia, 10: 363-368, 1982.

7. CARVALHO, A., FAZUOLI, L.C., COSTA, W.M. \& GUERREIRO (FILHO), o. Incorporação de fatores de resisténcia ao agente da ferrugem no café Mundo Novo. Congresso Brasileiro de Pesquisas Cafeeiras, Londrina, PR, 11: 183-185, 1984.

8. CARVALHo, A. \& KRUG, C.A. Agentes da polinização da flor do cafeeiro (Coffea arabica). Bragantia 9: $11-24,1949$.

9. CARVALHo, A., MEdiNa (FILHO), H.P. \& FAZUOLI, L.C. Genetic analysis of short stature characteristic in Coffea arabica. In Proc. ASIC Colloquium, Sal vador, BA, Brasil 10: 57, 1982 (Resumo).

10. CARVAlho, A., MEDina (FILHO), H.P. \& FAZUOLI, L.C. Evolução e melhoramento do cafeeiro. Colóquio so bre citogenética e Evolução de Plantas. ESALQ, P六 racicaba, SP, 1: 21, 1984. (Resumo).

11. CARVALHO, A. \& MÔNACO, L.C. Natural cross-pol1ination in Coffea arabica. Proc. XVI. Hort. Congr. Brusse1s, 4: 447-449, 1962.

12. CARVALHO, A. \& MÔNACO, L.C. Genetic relationships of selected Coffea species. Ciência e Cultura 19 (1): 151-165, 1967. 
13. CARVALHO, A., MONACO, L.C. \& FAZUOLI, L.C. Melhoramento do cafeeiro XL. Estudo de progênies e híbridos de café Catuai. Bragantia 38(229): 203216, 1979 .

14. CARVAlho, A., MONACO, L.C. \& VAN DER VOSSEN, H.A.M. Café Icatu como fonte de resistência a Colzetotrichum coffeanum. Bragantia 35: 343-347, 1976.

15. CARVALHO, A., SCARNARI, H.J., ANTUNES (FILHO), H. \& MONACO, L.C. Melhoramento do cafeeiro XXII: Resultados obtidos no ensaio de seleções regionais de Campinas. Bragantia 20: 712-740, 1961.

16. CARVALHO, A. \& OUTROS. Melhoramento do Caf eeiro IV: Café Mundo Novo. Bragantia 12: 97-129, 1952.

17. CARVALHO, A \& OUTROS. Melhoramento do Cafeeiro XIII: café Bourbon Amarelo, Bragantia 16: 411-454, 1957.

18. FAZUOLI, L.C. Resistance of coffee to the root-knot nematode species Meloidogyne exigua and $M$. incognita. p. 57. In Coloque International sur la Protection des Cultures Tropicales, Lyon, France, 1981.

19. FAZUOLI, L.C. Avaliação de progênies de café Mundo Novo (Coffea arabica). MS Tese, Escola Superior de Agricultura "Luiz de Queiroz", Universidade de São Paulo, Piracicaba, 1982.

20. KRUG, C.A. Controle de polinização nas flores do ca feeiro. Campinas, Instituto Agronômico, $12 \mathrm{p}$. (Bo1. Técn. 15).

21. KRUG, C.A. Melhoramento do cafeeiro: doze anos (1933-1944) de pesquisas básicas e aplicadas realizadas nas Seçoes de Genética, Café e Citologia do Instituto Agronōmico. Bol. Suptda. Café - São Paulo 20 (222): 863-872, (223): 979-992, (224): 1038-1046, 1945. 
22. KRUG, C.A. \& CARVALHO, A. Genetic proof of existence of coffee endosperm. Nature (London) $144: 515,1939$.

23. KRUG, C.A. \& CARVALHO, A. The Genetic of Coffee. Adv. Genet. 4: 127-158, 1951.

24. LONGO, C.R.L. Estudo de pigmentos flavonóides e sua contribuição à filogenia do gênero Coffea. Dout. Tese, Escola Superior de Agricultura "Luiz de Queiroz", Univ. São Paulo, 1972.

25. MAGLIO, C.A.F.P. Morfologia dos cromossomos nucleolares em fase de paquiteno no gênero Coffea. UNICAMP, Instituto de Biologia. Tese dissertação para obter título Mestre. 92p. 1983 (datilografa da, não publicada).

26. MAZZAFERA, P., GUERRE IRO (FILHO), 0. \& CARVALHO, A. Estudo da coloração verde do grão de café. Deter minação dos flavonóides e clorofila. Congresso Brasileiro de Pesquisas Cafeeiras. Londrina, PR . 11 : $178-181,1984$.

27. MEDINA (FILHO), H.P., CARVALHO, A. \& MONACO, L. C. Melhoramento do cafeeiro XXVII: Observações sobre a resistência do cafeeiro ao bicho mineiro. Bragantia 36: 131-137, 1977.

2Q. MEDINA (FILHO), O., CARVALHO, A., SONDAHL, M. R., FAZUOLI, L. C. \& COSTA, W.M. Coffee breeding and related evolutionary aspects. Plant Breeding Reviews, AVI, USA, 2: 157-193, 1984.

29. MENDES, A.J.T. Plantas monossômicas em Coffea arabi ca. Ciência e Cultura 3: 26, 1951.

30. MENDES, A.J.T. Advances in Cof $\mathrm{fee}$ Production Technology. Recent advances in our knowledge of coffee trees. 3 Cytology. Coffee \& Tea Industries $81: 37-41,1958$. 
31. MENDES, A.J.T., MEDINA, D.M. \& CONAGIN, C.H.T. Cito logia do desenvolvimento dos frutos sem sementes no café Mundo Novo. Bragantia 13: 257-279, 1954.

32. MENDES, A.J.T. Ensaio de variedades de cafeeiros. Campinas, Instituto Agronômico, 1939, 36p. (Bol. Técn. 65).

33. MONACO, L.C., CARVALHO, A. \& FAZUOLI, L.C. Melhoramento do cafeeiro. Germoplasma do café Icatu e seu potencial no melhoramento. Congresso Brasileiro de Pesquisas Cafeeiras, Poços de Caldas, MG, 2: 103, 1974. (Resumo).

34. MONACO, L.C., CARVALHO, A. \& ROCHA, T.R. Melhoramen to do cafeeiro XXVIII. Ensaio de Seleções Regionais de Mococa. Bragantia 24:9-27, 1965.

35. SONDAHL, M.R. and SHARP, W.R. High freguency induction of somatic embryos in cultural leaf explants of $C$. arabirea L. 2. Pflanzenphysiol. 81: $395-408,1977$. 